\title{
Coulisses
}

Revue de théâtre

7 | Printemps 1993

Varia

\section{Une perfection rigide : Les Ubs d'après A. Jarry par Denis Marteau}

Espace Planoise, 21 au 24 octobre

\section{Anne-Marie Tournier}

\section{(2) OpenEdition}

\section{Journals}

Édition électronique

URL : http://journals.openedition.org/coulisses/2123

DOI : 10.4000/coulisses. 2123

ISSN : 2546-9460

\section{Éditeur}

Presses universitaires de Franche-Comté

Édition imprimée

Date de publication : 1 avril 1993

Pagination : 7

ISSN : 1150-594X

\section{Référence électronique}

Anne-Marie Tournier, « Une perfection rigide : Les Ubs d'après A. Jarry par Denis Marteau », Coulisses [En ligne], 7 | Printemps 1993, mis en ligne le 15 mars 2019, consulté le 31 octobre 2019. URL : http:// journals.openedition.org/coulisses/2123; DOI : 10.4000/coulisses.2123

Ce document a été généré automatiquement le 31 octobre 2019

Coulisses 


\title{
Une perfection rigide : Les Ubs d'après A. Jarry par Denis Marteau
}

\author{
Espace Planoise, 21 au 24 octobre
}

Anne-Marie Tournier

1 En adaptant différents textes d'Alfred Jarry dont Ubu Roi et Ubu enchaîné, Marteau a voulu mettre en avant le côté tout à fait inhumain du père et de la mère Ubu. Le partipris d'en faire des "pantins » est tout-à-fait réussi, tant dans la gestuelle que dans l'absence d'émotion des personnages. Ils ont tous l'air d'être manipulés : déplacements, répliques, tout se déroule avec une exactitude de métronome : précision des gestes, du jeu des acteurs. La mère Ubu - jouée par un homme, ce qui renforce le côté asexué de ces marionnettes vivantes - est en cela une prouesse d'acteur : rien n'est dû au hasard, toute grimace, toute parole est dosée et pensée. Le père Ubu, est parfaitement ignoble : son visage, grimaçant sous le maquillage, nous le laisse deviner avant même qu'il entre en action. L'excès de monstruosité nous fait rire, et toute cette mécanique de précision nous laisse pantois.

2 Mais cette mise en scène, qui veut mettre en relief "1'inhumanité » de ces êtres, se laisse prendre à son propre jeu. Le côté creux des personnages seul apparait. Le procédé s'use à force d'être utilisé.

3 Je suis ressortie ébaubie par tant de technicité mais je n'étais pas émue. Pourtant, cette rigidité, ces personnages monstrueux auraient pu me bouleverser... Peut-être Denis Marteau s'est-il laissé prendre au piège de sa mise en scène ? Car les acteurs ne nous renvoyaient pas cette émotion propre au Théâtre. Les Ubs fut un magnifique spectacle mais sans doute un peu trop uniquement plastique. 
Les Ubs

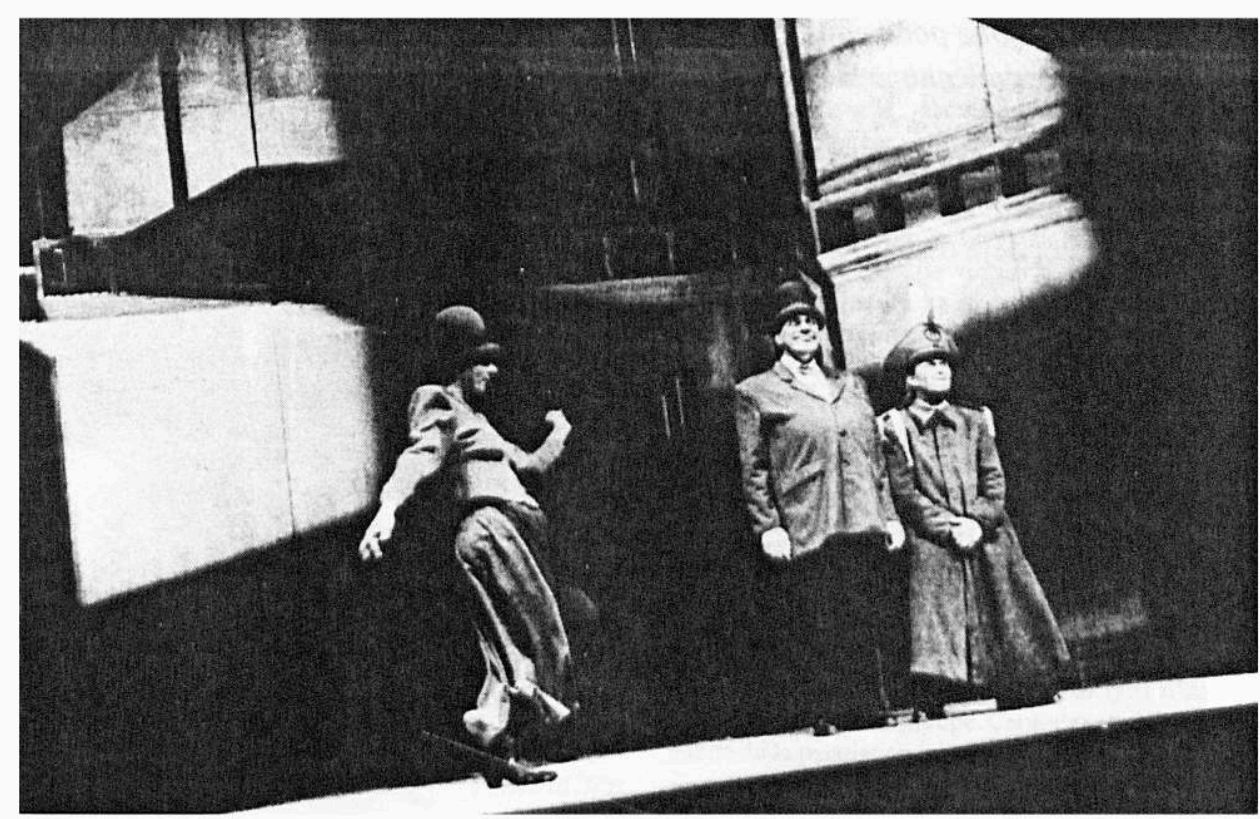

Josée LAMBERT

\section{AUTEURS}

\section{ANNE-MARIE TOURNIER}

Titulaire d'un D.E.A. de Lettres Classiques, M.A. dans différents lycées, elle anime un club théâtre. 